\title{
As razões do populismo
}

\section{The reasons for populism}

\author{
Léo Peixoto Rodrigues
}

Professor, Programa de Pós-graduação em Sociologia/Universidade Federal de Pelotas.

leo.peixotto@gmail.com

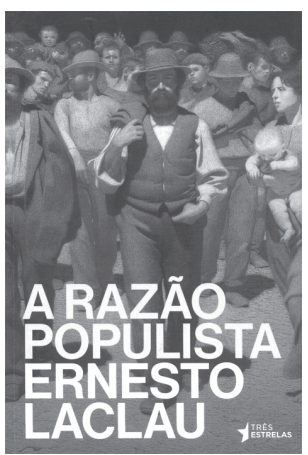

LACLAU, Ernesto. A razão populista. São Paulo: Três Estrelas. 2013. 384p.

Chega ao público brasileiro - e aos luso-brasileiros - a obra intitulada A razão populista, de Ernesto Laclau, publicada pela Editora Três Estrelas, de São Paulo. O livro tem quase quatrocentas páginas e apresenta excelente acabamento e sugestiva capa que traz a forte imagem neoimpressionista de Giuseppe Pellizza da Volpedo O quinto Estado, muito adequada a seu instigante conteúdo. Essa imagem também ilustrou a capa da edição originalmente publicada em inglês pela Verso, em 2005, sob o título On populista reason.

A edição brasileira conta com a competente apresentação de dois grandes especialistas do nosso país sobre o pensamento de Ernesto Laclau, Alice Casimiro Lopes, da Universidade do Estado do Rio de Janeiro, e Daniel de Mendonça, da Universidade Federal de Pelotas. Lopes e Mendonça situam a evolução do pensamento do autor no escopo da filosofia política e da ciência política, e apresentam seus principais conceitos, de modo simples, objetivo e sem prescindir do rigor proposto por Laclau na sua original teoria do discurso. Como não poderia deixar de ser, a edição em língua portuguesa também traz a "Introdução à edição brasileira". Aí Laclau (p.23) declara que a crise da esquerda europeia está vinculada ao fato de não ter conseguido evitar a cilada entre o "puramente liberal" e os "puros protestos" que se esgotam na autorreferência. Acrescenta que "desse ponto de vista, o atual populismo radical latino-americano constitui um caminho potencialmente mais bem sucedido para enfrentar os futuros políticos que se abrem a partir da presente conjuntura crítica".

A obra está organizada em três partes centrais, além de algumas "Observações finais" voltadas para o pensamento de autores de renome internacional, nos âmbitos da ciência e da filosofia políticas, tais como Slavoj Zizek, Michael Hardt, Antonio Negri e Jacques Rancière. A primeira parte, escrita sob o título "A denegrição das massas", Ernesto Laclau inicia por uma revisão bibliográfica concernente ao debate sobre populismo. Sem pretender algo amplo e aprofundado, posto que o próprio autor reconhece sua brevidade e óbvia incompletude (p.51), 
ele se detém nos textos de Margaret Canovan e de Donald MacRae, ambos pertencentes à coletânea organizada por Ghita Ionescu e Ernest Geller, além do ensaio de Peter Wiles, para criticar a dificuldade desses autores em atribuir um sentido ao termo populismo, não obstante a criação de uma "tipologia", para lhe atribuir significados possíveis. Segundo Laclau (p.41), "o problema que se apresenta com essa caótica enumeração [tipológica] é, sem dúvida, o fato de que os movimentos mencionados [na citação de MacRae] possuem poucos ou nenhum dos traços do populismo".

A partir de então, Ernesto Laclau aponta a necessidade de buscar alternativas às armadilhas nas quais caíram os autores mencionados ao tentar encontrar uma definição menos equívoca da noção de populismo. Para tanto, propõe que se considerem duas importantes questões: (1) questionar, ao se buscar definir o populismo, o quanto não se o estaria tirando da esfera de apreensão de um tipo específico de racionalidade, em que a lógica da política estivesse sendo desconsiderada a priori (p.52); e, (2) a "denegrição discursiva" do populismo não estaria necessariamente na construção das categorias "vagueza" e "imprecisão", mas, contrariamente, no fato de as assumir "como consequência da própria realidade social que, em algumas situações é vaga e indeterminada... (p.53). O que de fato Laclau está propondo é que se resgate o populismo de uma posição marginal, em termos da ciência política, à qual foi relegado, para concebê-lo como uma dimensão lógica e portanto racional do fazer política.

Ainda na primeira parte, nos capítulos segundo e terceiro, o autor avança em relação às suas duas questões anteriores, recorrendo a algumas posições do psicólogo social francês Gustave Le Bon, no que se refere à psicologia das multidões. Ao citar Le Bon, para quem "o poder das palavras está unido às imagens que elas evocam e é totalmente independente do seu significado real" (p.58), Laclau destaca que, na perspectiva contemporânea, Le Bon está fazendo referência tanto à "ausência de fixidez da relação entre significante e significado ... [como] ao processo de sobredeterminação por meio do qual certa palavra condensa uma pluralidade de significados" (p.58). Com isso, Laclau busca demonstrar que já nos escritos de Le Bon era possível verificar que o discurso da multidão está pautado por uma relação palavra/imagem e por uma emergência de ilusões dessa própria relação.

Após a crítica recebida por Erika Apfelbaum e Gregory McGuire - especificamente sobre o conceito de "multidão", desenvolvido e utilizado não apenas por Le Bon, mas também por Gabriel Tarde - quanto ao fato de esse termo estar carregado (e de ser empregado nesse sentido) de valores "destrutivos", o debate sobre a psicologia das massas passa a vincular-se a duas escolas centrais, também francesas: Salpêtrière (com Jean-Martin Charcot) e Nancy (com Liebeault). A primeira tem caráter estritamente fisiológico, ao passo que o da segunda é psicológico. Entretanto, foi com a mudança na teoria psiquiátrica e com a noção de racionalidade não apenas individual, mas também atribuída aos grupos, que se ampliaram os estudos sobre o comportamento das massas. De acordo com Ernesto Laclau foi com Sigmund Freud que se obteve "o mais radical avanço", com a obra Psicologia das massas e a análise do eu. Nesse livro Freud observa que o modelo (um objeto, um ajudante, um oponente...) a que o indivíduo está invariavelmente ligado desde o começo de sua vida borra o contraste entre psicologia individual e psicologia social. Essa perspectiva freudiana está ligada à diferença entre impulso social e impulso narcisista. É aí que entra a questão da identificação, posto que Freud, segundo Laclau, vai argumentar que "os laços emocionais que unem o grupo constituem, obviamente, 
impulsos de amor que foram desviados do seu objetivo original [o libidinoso] e que, de acordo com Freud, seguirão um padrão muito preciso: o da identificação" (p.99).

Ernesto Laclau utiliza-se desse excurso sobre a psicologia das massas (ou, como foi chamada inicialmente, psicologia das multidões) com objetivos teóricos muito claros: para demonstrar que as massas possuem lógica própria, complexa e que tem sido um relevante objeto de estudo das ciências humanas; para reafirmar a necessidade de abordagem renovada do populismo, como fenômeno que deve ser mais bem compreendido pela ciência política; e para resgatar o populismo, como objeto de estudo, da denegrição (termo por ele usado constantemente) a que tem sido relegado junto ao que chama de "a denegrição das massas" (p.111).

Na segunda parte da obra, A construção do "povo", Laclau retoma os questionáveis pressupostos que a literatura tem trazido sobre o populismo, já discutidos - a visão pejorativa de que é vago e indeterminado; que não passa de retórica. Alicerçado em suas premissas iniciais de que a vagueza e a indeterminação refletem uma realidade social, que a retórica, vista como estrutura conceitual, nutre-se de dispositivos teóricos, Laclau reafirma sua tese central: "o populismo é o caminho para se compreender algo sobre a constituição ontológica do político enquanto tal” (p.115). É então, no quarto capítulo, que dá início a essa segunda parte, que o autor retoma algumas categorias teóricas fundantes de sua teoria do discurso, tais como discurso, hegemonia, identidade etc., renovando seus significados e considerando-as, ele mesmo, além de outros teóricos, pós-marxistas, pós-estruturalistas e pós-fundacionistas. ${ }^{1}$

A primeira dessas categorias que marcam a centralidade de sua teoria é a noção de "discurso", para o autor, a única possibilidade de estruturação do fenômeno político. Em outros termos, o político como fenômeno social está imerso inexoravelmente no espaço da discursividade, sem que haja a possibilidade do extradiscursivo. Além disso, ele salienta, “por discurso ... não tenho em mente algo que é essencialmente relativo às áreas da fala e da escrita, mas quaisquer conjuntos de elementos nos quais as relações desempenham o papel constitutivo" (p.116). Segundo Laclau, amparando-se na linguística saussuriana, relação é sempre uma operação de distinção e é justamente esse o lócus da objetividade. Nesse sentido, o agir é discursivo, uma vez que é uma operação de distinção relativamente a outras ações.

A segunda categoria, também explicada em trabalhos anteriores de Laclau, aparece em A razão populista composta por dois conceitos articulados entre si e interdependentes: "significantes vazios" e "hegemonia". O autor chama de significante vazio um conjunto (discursivo) puramente diferencial, cuja totalidade, de certa forma, faz parte de cada "ato individual de significação". Em outras palavras, significantes vazios constituem-se em uma cadeia de discursos articulados entre si que, embora sejam distintos uns dos outros, unemse, em um determinado momento, formando uma totalidade (unidade) hegemônica. Ao se estabelecerem os limites dessa totalidade, também se está estabelecendo a diferenciação de "outra coisa" que não é essa totalidade e que dela necessita ser excluída para que de fato seja um "verdadeiro exterior" nos termos de Laclau, posto que faz parte de um limite de diferenciação. "Isso, entretanto," argumenta o autor, "cria um novo problema: vis-à-vis o elemento excluído, todas as outras diferenças se equivalem mutuamente. Elas são equivalentes em sua comum rejeição à identidade excluída" (p.119). Assim, outro conceito fundamental para sua explicação de populismo entra em cena: a "relação equivalencial". A equivalência é aquilo que subverte a diferença, fazendo com que identidade e diferença sejam construídas a 
partir desta tensão: lógica da diferença e lógica da equivalência. Isso significa que, se tivermos dois discursos que se antagonizam, um "pró" e outro "contra" determinada demanda, eles serão equivalentes entre si na cadeia discursiva que vai construir sua totalidade. É nesse sentido que Ernesto Laclau vai falar em lógica da diferença e lógica da equivalência, posto que não há nada (nenhum fundamento) que garanta maior legitimidade a um, em detrimento de outro, no campo da discursividade. Então, "hegemonia", nos termos propostos pelo autor, seria: "a operação de assumir, por meio de uma particularidade, um significado universal incomensurável" (p.120) - a relação incomensurável entre universal e particular que se constitui em uma de suas principais teses. Em outros termos, toda identidade hegemônica torna-se um "significante vazio".

A "retórica", sua terceira categoria teórica, faz referência ao processo em que "um termo literal é substituído por um temo figurativo" (p.120). Explica o autor que na retórica clássica, quando um termo figurativo não podia ser substituído por um literal, era denominado "catacrese" (a "perna" de uma mesa, por exemplo). É valendo-se dessa exposição que Laclau vai explicar que a "construção política do 'povo' - 'povo' como um termo necessário de ser nomeado, mas impossível de o fazer a partir de um marco zero de significação - terá de se valer fundamentalmente da catacrese" (p.121). Assim, segundo o autor, é precondição de qualquer processo significativo que a operação hegemônica obedeça cada vez mais à catacrese.

Esses conceitos fundamentais da teoria do discurso vão ser essenciais para que ele estabeleça sua "lógica populista", ou seja, sua "razão populista". Essa razão vai estar ancorada nos "laços de equivalência" e na necessidade de uma "diferenciação interna". Isso significa que quando as demandas - agora não mais como sentimentos vagos de solidariedade se apresentam com características de fundamento, cristalizando-se num tipo específico de identidade discursiva - que pode ser um "nome", o "povo", por exemplo -, podem estruturar-se como uma "cadeia de equivalência", sobretudo quando as demandas não são mais atendidas pelas equivalências da representação democrática. Ele exemplifica essa questão quando faz referência às "fraturas" da tessitura social e ao consequente surgimento de identidades populares: "à função de tribuna", do partido comunista francês (p.142); do cartismo britânico das décadas de 1830 e 1840 (p.137-150). O autor argumenta que a "fratura", em sua raiz, traz a experiência da "falta" (no sentido lacaniano) que se constitui "em uma brecha que emergiu na harmoniosa continuidade do social ... sem essa ruptura inicial de algo na ordem social ... não existe possibilidade de um antagonismo, de uma fronteira ou, em última instância, de "povo'" (p.140).

Tem-se aí um aspecto importante sobre o funcionamento da articulação discursiva e de sua formação. Laclau traz a noção de "demanda social" como uma espécie de "unidade mínima" para a "ocorrência do fenômeno" político. Essa demanda, quando não atendida, pode transformar-se - ao aglutinar mais significações de outras demandas também não atendidas - em uma longa cadeia articulatória. Portanto, transforma-se em um discurso que sempre vai tender à constituição de uma "relação equivalencial", deflagrando um corte "antagônico" em relação àquilo que impede o atendimento das demandas. Um exemplo dessa ampliação de sentidos promovida pela articulação é o da campanha Diretas Já, ocorrida no Brasil em 1984 - analisada por Mendonça (2004), justamente a partir da aplicação da teoria de Laclau. Naquele momento, a demanda específica "votar para presidente" tornou- 
se o centro articulador de uma série de outras demandas, tais como reforma agrária, direitos civis, liberdade de expressão, democracia etc. Essa lógica é extensiva ao populismo, aqui já entendido como um tipo de fenômeno político.

O autor passa então a descrever, valendo-se de alguns exemplos, o modo como, a partir da heterogeneidade social e de "significantes flutuantes", uma demanda articula-se em uma cadeia de equivalência. Antes, porém, apresenta dois diagramas: um mais simplificado, que, aliás, aparece um de seus mais conhecidos trabalhos (Laclau, Mouffe, 2004), cujo objetivo central é ilustrar o "significante vazio" (p.196). O outro tem por finalidade ilustrar como demandas antagônicas distintas podem constituir o "povo", como ator histórico, dependendo do resultado de disputas hegemônicas. É através da articulação conceitual - significante vazio, significante flutuante, articulação hegemônica (luta) e antagonismo - que Laclau vai afirmar que: “'todas' as lutas são, por definição 'políticas' ... Isto quer dizer que o político tornou-se sinônimo de populismo? Sim no sentido que eu concebo este último conceito. Uma vez que a construção do 'povo' é um ato político par excellence, em oposição a uma pura administração de um quadro institucional estável" (p.228; destaques do autor).

Na terceira parte da obra - que diz respeito diretamente ao resgate do populismo da "perspectiva menor" a que tem sido submetido na teoria política - Ernesto Laclau amplia o debate, dessa vez com autores que de certa forma compactuam com algumas de suas ideias com relação ao reducionismo do conceito de populismo, como Yves Surel. Também discute de forma "mais livre" (menos vinculada à estrutura conceitual que dá sustentação às suas teses iniciais) outras perspectivas relativas ao populismo, vinculando-as a diferentes episódios históricos. No oitavo capítulo, no final da terceira parte, cumpre de forma exemplar o prometido em seu início: faz uma microanálise - como observa, “[o que poderia vir a ser] uma exploração empírica do populismo 'realmente existente'” (p.253).

Trata-se de trabalho de fôlego, muito bem referenciado e enriquecido com exemplos de diferentes momentos históricos que dão importante sustentação aos argumentos do autor, um trabalho denso, que aplica a diversidade conceitual da teoria do discurso, proposta por Laclau, à análise do populismo, renovando completamente seu entendimento, como dimensão do político. Por esse motivo constitui-se num cabedal teórico de difícil apreensão por aqueles não iniciados nessa escola; sobretudo, pelo fato de o objetivo do autor, nessa obra, não ser especificamente apresentar os principais conceitos por ele forjados ao longo de mais de três décadas.

Ernesto Laclau coloca nesse livro todo o amadurecimento de seu pensamento político, expresso na urdidura conceitual que compõe a sua teoria do discurso. De fato, como já observado pelos apresentadores, A razão populista vem preencher importante lacuna teórica na literatura que trata do populismo. Constitui-se em referência obrigatória a todos que desejam discutir o populismo, seja por algum viés teórico, seja por explorações empíricas.

\section{NOTA}

${ }^{1}$ Para aprofundamento do debate, ver Mendonça, Rodrigues (2008). 


\section{REFERÊNCIAS}

LACLAU, Ernesto; MOUFFE, Chantal.

Hegemonía y estrategia socialista: hacia una radicalización de la democracia. Buenos Aires: Fondo de Cultura Económica. 2004.

MENDONÇA, Daniel; RODRIGUES, Léo P. Pós-estruturalismo e teoria do discurso: em torno de Ernesto Laclau. Porto Alegre: EDIPUCRS. 2008.
MENDONÇA, Daniel.

Tancredo Neves: da distensão à Nova República. Santa Cruz: Editora da Universidade de Santa Cruz do Sul. 2004. 